\title{
Wettability Measurement and Its Impact in Converted Capillary Pressure Curves
}

\author{
Vanessa Costa, Roseane Missagia, Marco Ceia, UENF/ LENEP.
}

Copyright 2019, SBGf - Sociedade Brasileira de Geofísica

This paper was prepared for presentation during the $16^{\text {th }}$ International Congress of the Brazilian Geophysical Society held in Rio de Janeiro, Brazil, 19-22 August 2019.

Contents of this paper were reviewed by the Technical Committee of the $16^{\text {th }}$ International Congress of the Brazilian Geophysical Society and do not necessarily represent any position of the SBGf, its officers or members. Electronic reproduction or storage of any part of this paper for commercial purposes without the written consent of the Brazilian Geophysical Society is prohibited.

\section{Abstract}

As oil production tends to decrease after a time of exploitation, industry has been investing in recovery methods. These methods commonly inject fluids or chemicals in the reservoir and their efficiency will depend on the interaction of this fluid/chemical with the reservoir system (rock and present fluids). Since the wettability is the property that describes the preference of the rock to retain water, oil or none of them in its pore spaces, it influences directly the oil recovery mechanisms and becomes a reservoir valuable data. This work presents wettability values measured by the contact angle $(\Theta)$ method for both sandstone and carbonate outcrop samples before and after aging process, and also the interfacial tension $(\sigma)$ between the used fluids. These values were correlated to the mineralogy from the dataset. Results demonstrate the impact of wettability and interfacial tension in conversion of capillary pressure curves measured by the mercury injection method into a water-oil system, simulating in situ reservoir conditions.

\section{Introduction}

The wettability is an important property of a reservoir system. It's not a property of the rock alone: it depends on which fluids and rock are interacting in the system. It relates to the speed of the flow and distribution of the hydrocarbons through the interconnected pore spaces of the reservoir rock, thus influencing other properties of the system, such as the relative permeabilities to the different fluids and capillary pressure.

The range of wettability vary from strongly water-wet to strongly oil wet being the condition as follows: strongly to weakly water-wet, when the rock tends to retain water over oil, neutrally-wet, when no preference for any fluid is shown and weakly to strongly oil-wet, when it tends to retain oil over water. The system may also present a mixed-wettability in which the smaller pores of the rock are considered to be water-wet and the larger ones, oil-wet (Anderson, 1986). Lastly, the system may present a called fractioned wettability. In this case, some areas within the rock are considered to be water-wet while others are oilwet, being the reason for that, according to Tiab and Donaldson (2004), the presence of different minerals with different chemical properties in the rock surfaces. All these grades of wettability depend on the interaction between the present fluids and the rock and are an overall average characteristic of the microscopic heterogeneous system within the rock.

As this work intends to simulate reservoir systems, the wettability measurements were performed before and after core aging process, to analyze the influence of this procedure in the wettability values. The aging process is recommended to restore the original wettability of a reservoir core (Anderson, 1986).

The interfacial tension between two fluids relates directly to the capillary pressure in a reservoir. The immiscibility of fluids is the cause of capillaries phenomenon within a porous media. It also influences the adhesion tension, which is responsible for a fluid rise or depression in a capillary, affecting then the wettability of the system.

Both wettability and interfacial tension influence the capillary pressure in a reservoir. It is common practice to convert mercury injection capillary pressure (MICP) curves into water-oil systems to simulate the reservoir capillary pressure behavior, by using the Leverett's J-Function, which has $\theta$ and $\sigma$ as two input values as shown in Equation 1:

$\mathrm{J}=P c \frac{\sqrt{\frac{k}{Q}}}{\sigma \cos \theta}$,

in which, $\mathrm{k}$ is the sample permeability and $\varnothing$, its porosity.

This work presents the wettability values for sandstone and carbonate outcrops samples and the interfacial tension value between the used brine and oil. In addition, it demonstrates the impact of these two properties in the converted capillary pressure curves.

\section{Materials and Method}

The outcrops samples used in this work are three sandstones: Berea (BE), Nugget (NG) and Crab Orchard (CO) and one carbonate rock: Desert Pink (DP) from kocurek industries of approximately $0,8 \mathrm{~cm}$ long and 3, 8 $\mathrm{cm}$ in diameter. This work studied the wettability of two samples of the same rock, for comparison purposes. The preparation of the samples was as follows: first, they had their faces polished. Then, they dried in the oven and finally were saturated with brine.

The chosen fluids are the API brine (Hwang et. al, 2012; Zuniga et. al, 2016) and an oil mixture composed of crude oil $(20 \%)$ and diesel (80\%).

The applied method for the measurements of the samples wettability, both before and after the core aging, was the contact angle with the captive bubble technique. It this method, the sample is immersed in the denser fluid while a drop of the less dense one is put underneath the core. Then, one measures the contact angle between the drop and the sample surface, through the denser phase. 
To carry out these measures, an apparatus composed of a leveling table, a three-claw clamp, a spotlight and a glass vessel was built (Figure 1). Four shots were taken in the interval of 1:30 hour between them, with a photographic camera positioned in a leveling tripod base to monitor the drop behavior with time.

After the measurements of the contact angle, the samples were cleaned with pure water to take any impregnated salt of their surfaces off. Then, they were aged in the oil compound for forty days before the last measurements.

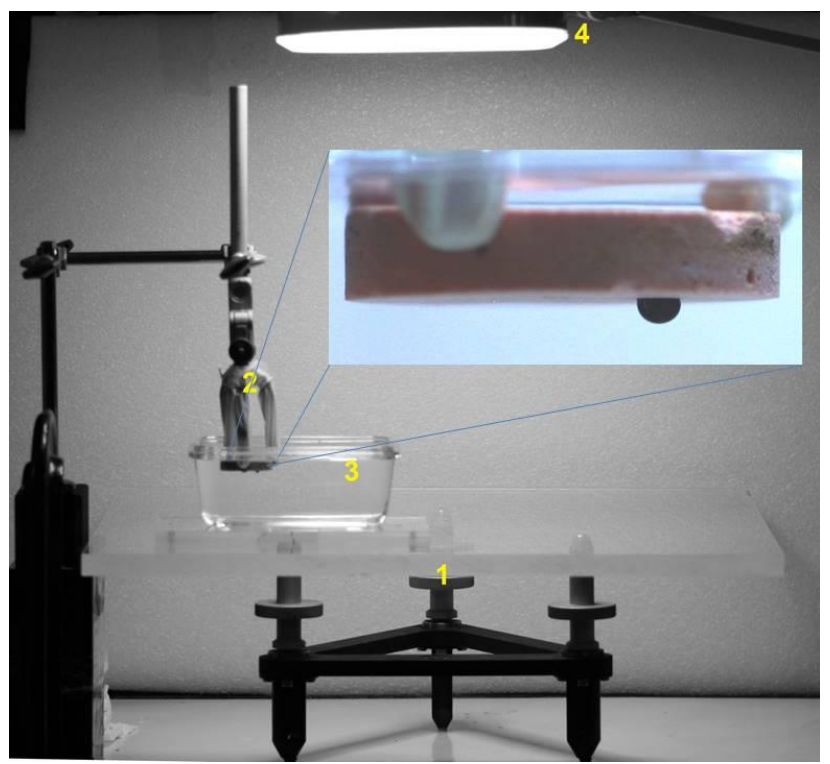

Figure 1: Apparatus for the measurements of the samples wettability. 1: leveling table, 2: three-claw clamp, 3: glass vessel and 4: a spotlight, with a zoom of the oil drop underneath the desert pink sample. From the authors

The software used to analyze the photos and calculate the contact angle values was the DSA4 from Kruss. The final contact angle value for each kind of rock is an average of the four measurements of the two samples, whether the oil drops present a constant behavior. If the shape of the drops showed any trend (being more oil-wet or water-wet) through time, the calculation of the average value took into account only the last measures of the two samples.

The classification of the wettability of the samples followed that proposed by Fanchi et al. (2010), shown in Table 1:

\begin{tabular}{c|c}
\multicolumn{2}{c}{ Table 1: Wettability Classification following Fanchi et al., 201 } \\
\hline Contact Angle (degree) & Wetting Condition \\
\hline $0-30$ & Strongly Water-wet \\
\hline $30-75$ & Moderately Water-wet \\
\hline $75-105$ & neutrally-wet \\
\hline $105-150$ & Moderately Oi-wet \\
\hline $150-180$ & Strongly Oil-wet \\
\hline
\end{tabular}

The method for measuring the interfacial tension was the $\mathrm{Du}$ Nuöy ring method using the K6 tensiometer, from Kruss (Figure 2). In this method, a thin wire ring, commonly platinum made, is immerged into the liquid of interest, parallel to its surface. Then, one slowly pulls it up until it detaches from the liquid. The value obtained is the maximum force $(F)$ required to pull the ring through the surface. The surface tension is given by Equation 2:

$$
\sigma=\frac{F . C}{2 \Pi(R i+R o)}=\frac{F . C}{4 \Pi R},
$$

where $\mathrm{Ri}$ and $\mathrm{Ro}$ are the inner and outer radius of the ring, which have very close values in this case. For the interfacial values (between two liquids), the denser phase must be put in the cleaned vessel first, then the ring is immerged in it and only after the lighter phase is carefully put in the vessel, not to contaminate the ring.

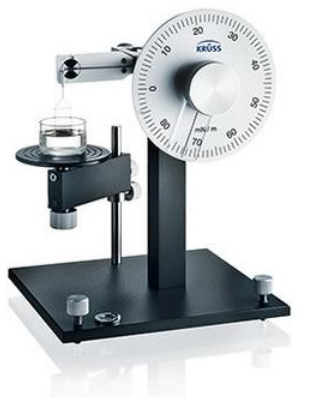

Figure 2: The K6 tensiometer. From: https://www.krussscientific.com/products/tensiometers/ force-tensiometer-k6/

Both the contact angle and the interfacial tension measurements were performed at ambient conditions.

Lastly, this work converted the MICP curves of the same type of rocks into the water-oil system, applying the $\mathrm{J}$ function and using the interfacial tension and contact angles modulus measured before. Here, the modulus of the contact angle was used to facilitate the visualization of the results. These curves were compared to those converted using standard values for $\theta$ and $\sigma$ : $30^{\circ}$ and $25 \mathrm{mN} / \mathrm{m}$. The mineralogy is that provided by kocurek while the texture classification was taken from Figueiredo (2015), which followed Folk (1980) for the sandstone samples and Dunham (1962) for the carbonate one. In addition, thin section analysis, from this last author, was added to support data correlation.

\section{Results}

Table 2 presents the mineralogy and texture classification for the studied samples, while Figure 3 shows their thin sections.

Table 2: Mineralogy, from Kocurek and textural classification, from Figueiredo, 2015

\begin{tabular}{c|c|c} 
Sample & Mineralogy compositon & Classification \\
\hline NG & $\begin{array}{c}91 \% \text { quartz; } 3 \% \text { k- feldspar, } \\
3 \% \text { mica, } 2 \% \text { kaolinite. }\end{array}$ & Quartz arenite \\
\hline BE & $\begin{array}{c}91 \% \text { quartz, } 1 \% \text { plagioclase, } \\
3 \% \text { k-feldspar, } 4 \% \text { kaolinite }\end{array}$ & Subarkose \\
\hline CO & $\begin{array}{r}92 \% \text { quartz; } 2 \% \text { k-feldspar, } \\
4 \% \text { mica, } 1 \% \text { kaolinite }\end{array}$ & \begin{tabular}{c} 
Subarkose \\
\hline DP
\end{tabular} \\
\hline
\end{tabular}




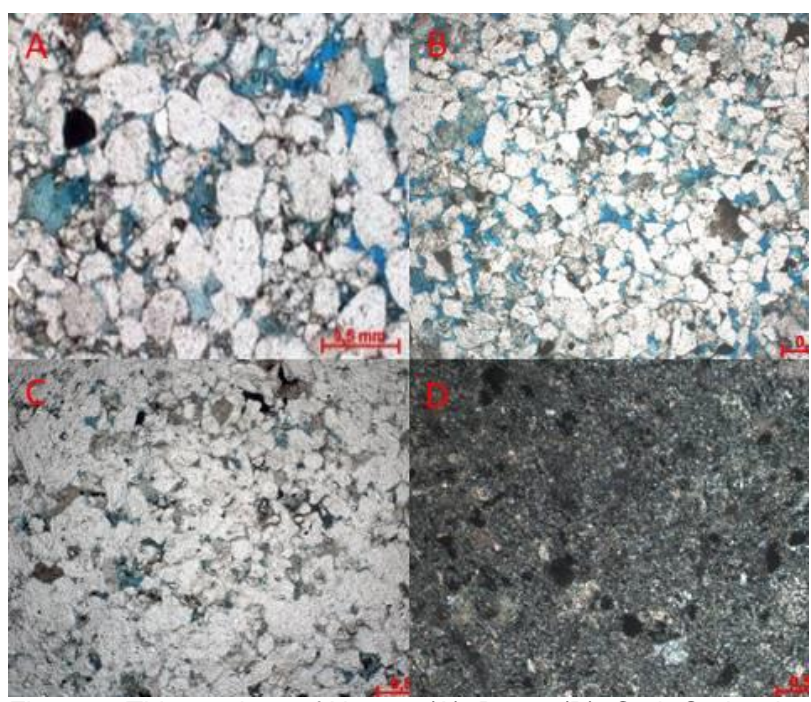

Figure 3: Thin sections of Nugget (A), Berea (B), Crab Orchard

(C) and Desert Pink (D). Modified from Figueiredo, 2015

According to Figueiredo (2015), the thin section analysis show that the Nugget and Berea samples have their quartz and mica grains individualized and preserved indicating a low to moderate mechanical compaction. The Crab Orchard's, in turn, suggests a more intense burial and chemical compaction, promoting a siliceous cement and reducing its porosity. Lastly, the Desert Pink thin section analysis indicates the presence of calcite in high crystallization state with presence of micrite.

Tables 3 and 4 present the wettability values, as well as their classification, for the measurements before and after the aging process, respectively.

Table 3: Contact angle values and their classification before the aging process

\begin{tabular}{c|c|c} 
Sample & $\boldsymbol{\theta}$ (degrees) & Classification \\
\hline NG & 40,68 & moderately water-wet \\
\hline BE & 41,3 & moderately water-wet \\
\hline CO & 32,55 & moderately water-wet \\
\hline DP & 109 & moderately oil-wet \\
\hline
\end{tabular}

Table 4: Contact angle values and their classification after the aging process

\begin{tabular}{c|c|c} 
Sample & $\boldsymbol{\theta}$ (degrees) & Classification \\
\hline NG & 143 & moderately oil-wet \\
\hline BE & 144,2 & moderately oil-wet \\
\hline CO & 160 & strongly oil-wet \\
\hline DP & 180 & strongly oil-wet \\
\hline
\end{tabular}

The value obtained for the interfacial tension between the used fluids was of $19,25 \mathrm{mN} / \mathrm{m}$ in $23,5^{\circ} \mathrm{C}$ temperature.

Figures 4-7 compare the capillary pressure curves of standard, pre aging and aged data for each rock:

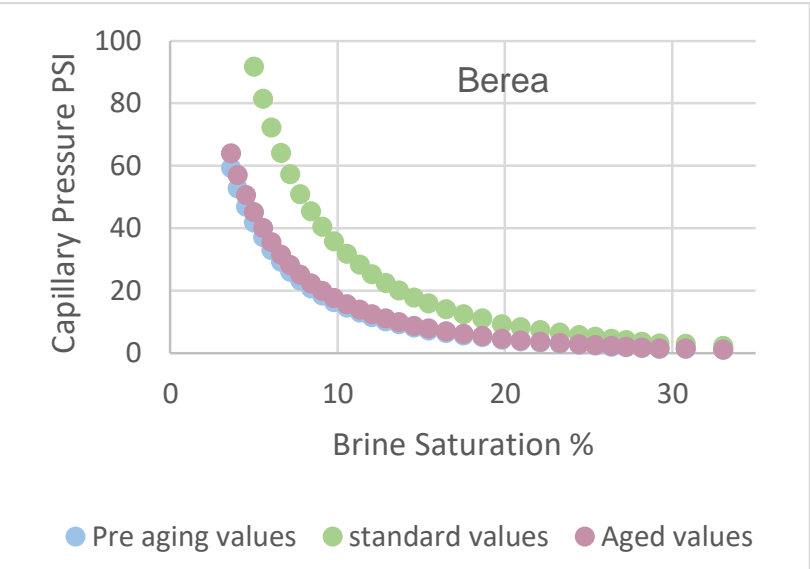

Figure 4: Capillary pressure $\mathrm{x}$ brine saturation of Berea sandstone

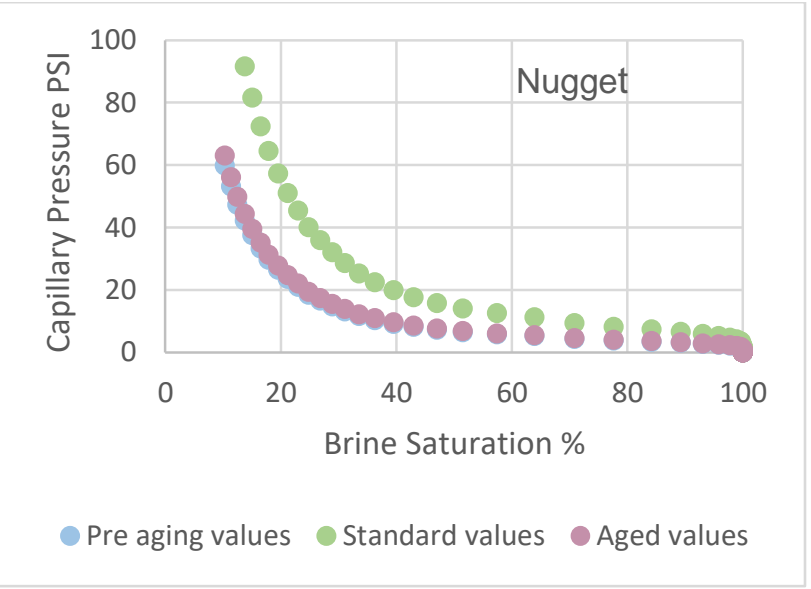

Figure 5: Capillary pressure $\mathrm{x}$ brine saturation of Nugget sandstone

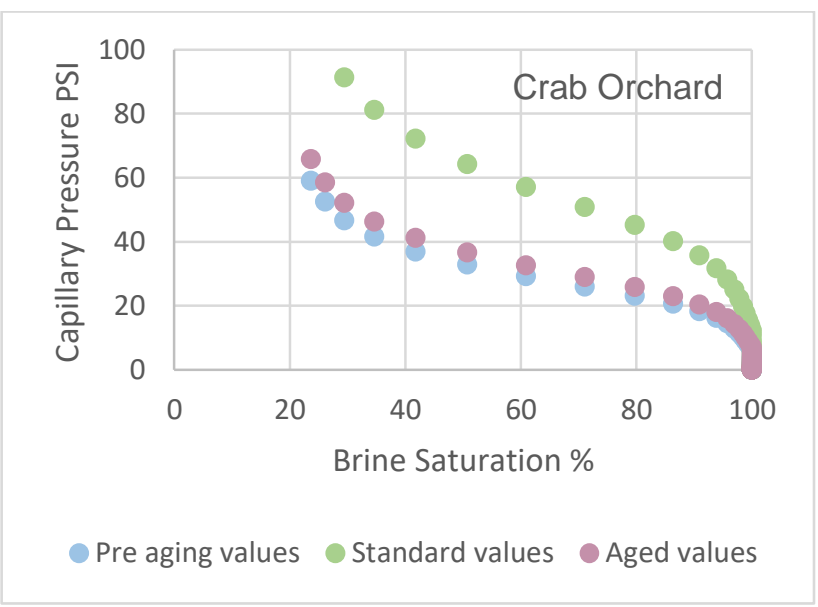

Figure 6: Capillary pressure $\mathrm{x}$ brine saturation of Crab Orchard sandstone 


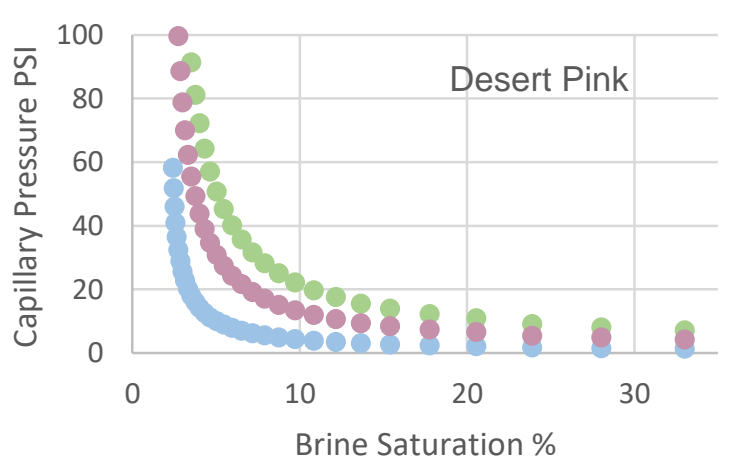

Pre aging values OStandard values Aged values

Figure 7: Capillary pressure $\mathrm{x}$ brine saturation of Desert Pink carbonate rock

\section{Discussion}

All the samples became more oil-wet after the aging process. The three sandstones showed water-wet behavior initially, changing to oil-wet after aging, while the carbonate sample presented an oil-wet behavior from the beginning. These results may be related to the composition of the crude oil. Core aging generally leads to alteration in wettability and this effect is associated with the content of asphaltenes and sulfur in the crude oil in concentration of $1 \%$ and $1,25 \%$ respectively (Cuiec, 1985 APUD KOVALEV, 2016).

The Nugget and Berea sandstones exhibited quite similar behavior in all the aspects: mineralogy composition, thin section analysis, contact angle values, both before and after aging, and the impact in capillary pressure converted curves.

The Crab Orchard sandstone, although presenting very similar mineralogy with the other sandstones, showed siliceous cementation, as indicated by the thin section analysis (Figure 3, C).

The desert pink sample also presents micrite cement, from the recrystallization of calcite. (Figure 3, D).

The obtained value for the Interfacial tension between the fluids was of $19,25 \mathrm{mN} / \mathrm{m}$, which is within the range of values found by Livingston (1938) to 34 different oil-brine pairs from several Texas fields at $21.1^{\circ} \mathrm{C}$ : from $13.6 \mathrm{mN} / \mathrm{m}$ to $34.3 \mathrm{mN} / \mathrm{m}$.

All the capillary Pressure curves were impacted when converted using the measured $\Theta$ and $\sigma$ instead of standard values. The Berea and Nugget samples did not show great difference in the curves using wettability values before and after aging. The Crab Orchard presented a slightly difference, while the Desert Pink sample displayed the greatest of them.

\section{Conclusions}

The sandstone outcrop samples studied presented waterwet behavior before the aging process, while the carbonate one showed an oil-wet condition when interacting with the chosen fluids.
All the samples became more oil-wet after aged, which might be related to the content of asphaltenes and sulfur in oil. The results in this work also suggest that cementation may be associated to the change of wettability.

The wettability and interfacial tension has big influence in converting MICP to water-oil systems using the J-function. Measured field data should be used to make an accurate reservoir characterization using converted capillary curves.

\section{Acknowledgments}

This study was financed in part by the Coordenação de Aperfeiçoamento de Pessoal de Nível Superior - Brasil (CAPES) - Finance Code 001. VC, RM and MC thank INCT/Geofisica and PRH-226-Petrobras for financial support; and also, RM and MC thank CNPq for their Research Grants of Productivity in Technological Development and Innovation - DT II.

\section{References}

ANDERSON, W.G. Wettability Literature Survey-Part 1: Rock/Oil/Brine Interactions and the Effect of Core Handling on Wettability. JPT, Richardson, v.38, p.11251144, Oct/1986.

FANCHI, J, R. Integrated Reservoir Asset Management: Principles and Best Practices. 1rst. Ed.Gulf professional publishing - Elsevier, 2010.

FIGUEIREDO, L.A.B. avaliação do sistema poroso e estimativa de permeabilidade utilizando equações modificadas de kozeny em rochas siliciclásticas e carbonáticas. Dissertation (MSc in Exploration and Reservoir Engineering) - LENEP, Universidade Estadual do Norte Fluminense. Macaé, p. 115, 2015.

HWANG, C; WANG, L; Lu, w; RUAN, G; KINI, G; XIANG, C; SAMUEL, E.L.G; SHI, W; KAN, A.T; WONG, M.S; TONSON, M.B; TOUR, J.M. Highly Stable Carbon Nanoparticles Designed for Downhole Hydrocarbon Detection - Electronic Supplementary Information. Energy Environ. Sci., 2012, 5, 8304-8309.

KOVALEV, K; FOMKIN, A; GRISHIN, P; KUROCHKIN, A; KOLESNIKOV, M; LEVCHENKO, A. Aged Carbonate Cores Wettability Verification. SPE Russian Petroleum Technology Conference and Exhibition, 24-26 October, 2016. Moscow, Russia.

LIVINGSTON, H, K. Surface and Interfacial Tensions of Oil-Water Systems in Texas Oil Sands. Pet. Tech, 1938, pp 1-13.

TIAB, D; DONALDSON, E.C. Petrophysics: Theory and practice of measuring reservoir rock and fluid transport properties. 2nd.Ed.Gulf professional publishing - Elsevier, 2004, p. 313-414.

ZUNINGA, C.A; GOODS, J.B; COX, J.R; SWAGER, T.M. Long-term High-temperature Stability of Functionalized Graphene Oxide Nanoplatelets in Arab-D and API Brine. ACS Appl. Mater. Interfaces, 2016, 8 (3), pp 1780-1785. 